\title{
REGIONAL RESILIENCE IN IRELAND AND THE EXISTENCE OF A TWO-TIER RECOVERY
}

\author{
BARRAí HENNEBRy \\ Institute of Socio-Economic Geography and Spatial Management, Adam Mickiewicz University, Poznań, \\ Poland
}

Manuscript received: September 3, 2018

Revised version: December 6, 2018

\begin{abstract}
HenNeBRY B., 2018. Regional resilience in Ireland and the existence of a two-tier recovery. Quaestiones Geographicae 37(4), Bogucki Wydawnictwo Naukowe, Poznań, pp. 99-110. 14 figs.

ABSTRACT: This paper focuses on the increasing regional disparities in Ireland, especially since the great recession and assesses the degree to which the recovery has been concentrated in urban areas. Ireland was initially affected by the recession to a greater extent than other countries but has recovered strongly. However, this recovery has not been evenly distributed, with some regions showing greater economic resilience. Using descriptive statistics of GDP per capita (PPP), GVA and employment, this paper examines the extent to which the recovery has been a two-tier recovery. The paper finds evidence to suggest that the recovery has been heavily concentrated in Dublin, and to a lesser extent in Cork and Galway, resulting in an urban-rural divide.
\end{abstract}

KEY wORDS: regional resilience, regional disparities, urban-rural divide, Ireland

Corresponding author: Barraí Hennebry, Institute of Socio-Economic Geography and Spatial Management, Adam Mickiewicz University, Poznań, ul. B. Krygowskiego, 61-680 Poznań, Poland; e-mail: hennebry@amu.edu.pl

\section{Introduction}

In regional economics, the most popular growth models are concerned with long-run growth and its effects on regional disparities. The neo-classical growth model (Solow 1956), due to the assumptions that labour remains constant and there are diminishing returns on investment, predicts that capital will flow to poorer regions. This influx of capital will result in poorer regions growing faster and therefore in the long-run we should witness convergence. This contrasts with the New Economic Geography model (Krugman 1991) which, due to transportation costs and economies of scale, predicts that investment will flow towards the region with the largest population. This will cause divergence between the core and the peripheral regions. These theories fail to predict what happens to regional disparities during a crisis. This gap has been filled in recent years by the emergence and advancement of theories and empirical studies regarding regional economic resilience, which focuses on how regions absorb and recover from recessions.

Since the recent recession of $2007 / 2008$ there has been an increased interest in regional resilience, both theoretical and empirical (Simmie, Martin 2010; Martin 2012; ESPON 2014). This paper hopes to add to that expanding body of literature by reviewing the experiences of the Irish economy in the lead up to and since the recent recession. Focusing on Irish NUTS 3 regions, this paper will examine the regional disparities across Ireland from 2000 to 2014 and explore to what extent the recession has caused an increase in regional disparities.

Ireland is an interesting case to study for several reasons. It was one of the countries 
most negatively affected by the recession in the European Union (EU) and was often grouped alongside Portugal, Italy, Greece and Spain to be given the acronym 'PIIGS'. These were considered the worst affected countries in the EU. However, Ireland has experienced a significant recovery from the recession which has been dubbed by some in the media as the 'Celtic Phoenix' (Brady 2014; Reilly 2014). In 2014, the then German finance minister, Wolfgang Schauble, even claimed that Germans were 'jealous' of the economic growth figures that were being achieved by Ireland (O'Hora, Kelpie 2014). This supposed 'miraculous' recovery has not been without its critics, with some claiming that in Ireland it has been a two-tier recovery with the growth being concentrated in Dublin (and some other urban centres), while the rest of the country, especially rural areas, continue to fall further behind (Weston 2015). This paper will examine the validity of the argument that Ireland is experiencing a two-tier recovery, with urban regions being more resilient, by analysing the changes in regional disparities to see to what degree the recovery has been concentrated in urban centres. The remainder of the paper is structured as follows: Section 2 will examine the literature on regional resilience to provide a working definition to be used in the context of this paper. Section 3 will outline the methodology for this paper. Section 4 will give a brief overview of the Irish economy from 2000 to 2014. This section will compare the experience of the Irish economy with that of the other 'PIIGS' to see if the Irish recovery has been exceptional. Section 5 will examine the changes in regional disparities across Irish NUTS 3 regions focusing on three indicators; gross domestic product (GDP) per capita (purchasing power parity), gross value added (GVA) and employment. This will show which regions were worst affected by the recession and which regions showed the greatest resilience, showing if there is validity to the claims of a two-tier recovery. Section 6 will discuss the findings and draw some conclusions from the paper as well as recommend areas of further research.

\section{Defining regional economic resilience}

Although growth theories and economic models tend to focus on the long-term determinants of growth, there has been an increased focus on economic resilience. Hassink (2010: 45) has stated that one of "the most intriguing questions in economic geography is why some regional economies manage to renew themselves, whereas others remain locked in decline". Even with this growing interest, regional economic resilience is still a relatively new area of research and as such definitions and theories tend to vary somewhat between different studies. It is therefore necessary to set out the exact definition of regional resilience and theoretical underpinnings of this paper.

The conceptual framework of this paper will largely be based on the work of Martin and Sunley (2014). As noted in their study, notions of regional economic resilience tend to be influenced by three distinct but similar definitions, which all come from other fields of study. Firstly, there is the definition which comes from engineering which sees resilience as the ability to bounce back or recover from a shock. It is important to note that this definition assumes a single equilibrium point and the resilience is measured by the "speed of return to equilibrium" (Holling 1996: 33). This fits well with a neo-classical or traditional view of economics where an economy should have one equilibrium point and will naturally move towards this point. Any shock or recession which causes a deviation from this point will be short lived and is seen as the exception to the rule. Then, there is the ecological definition which considers resilience to be the extent to which a system has the ability to absorb shocks before changing its structure (Holling 1973). This definition does not assume a single equilibrium, it instead assumes multiple equilibriums. This means that shocks have the ability to push regions into a different, lower equilibrium point (Davoudi 2012). The final definition comes from the psychological sciences and organisational theory which considers resilience to be the ability to adapt in anticipation of, or response to, shocks. This is also referred to as 'evolutionary resilience' (Davoudi 2012) and lends itself very well to the evolutionary economic approach. Here it is assumed that there are no fixed equilibrium points but that the economy is constantly evolving as it is seen as being "complex, non-linear, and self-organising, permeated by uncertainty and discontinuities" (Berkes, Folke 1998: 12).

Although there are similarities and crossovers between these definitions, and they can be useful, 
it is still necessary to define resilience specifically in the context of regional economics. Martin and Sunley (2014) created the following definition, and it is this definition which will be used in this paper:

"the capacity of a regional or local economy to withstand or recover from market, competitive and environmental shocks to its developmental growth path, if necessary by undergoing adaptive changes to its economic structures and its social and institutional arrangements, so as to maintain or restore its previous developmental path, or transit to a new sustainable path characterized by a fuller and more productive use of its physical, human and environmental resources" (p. 13).

\section{Measuring regional economic resilience}

In terms of measuring regional resilience, it is also noted by Martin and Sunley (2014) that there are a variety of techniques used in the study of regional resilience from descriptive case studies to sophisticated econometric models. They are also studied at different levels from municipality (Lapuh 2018) to NUTS 2 regions (ESPON 2014). Each approach has its own merits and it largely depends on the individual case as to which option is best. Due to the small size of Ireland, which only has eight NUTS 3 regions, the statistical significance of econometric models will be low and open to criticism. Therefore, this research is a case study of the Irish regions' response to the crisis using descriptive statistics. NUTS 3 regions are used as this is the best for data availability. The data used come from the Eurostat database.

Different indicators are often used as measures of resilience. This study will use the three most popular: GDP per capita (PPP), employment (both used by ESPON 2014), and GVA (as used by Lapuh 2018). For GDP per capita (PPP) two methods of measuring changing regional disparities are used. Firstly, the arithmetic mean deviation of regional GDP per capita from the national figure is used, this is the same methodology as used by Easterlin (1958). This shows the average difference between regions' GDP per capita and the national figure. If this is increasing then there are increasing regional disparities and if it is falling, then there are decreasing regional disparities. The second method used for checking for increasing regional disparities is similar to that of Dyba et al. (2018) and Barro's (1997) test for convergence. Barro (1997) represents the model in the following equation form:

$$
D y=f\left(y, y^{*}\right)
$$

where $D y$ is the growth rate of GDP per capita, $y$ is the starting level of GDP per capita, and $y^{*}$ is the steady-state or long-run level of GDP per capita. This means that at a given level of $y^{*}$ "a higher starting level of per capita output, $y$, implies a lower per capita growth rate" (Barro 1997: 9). This means that we should expect convergence.

For examining employment and GVA as measures of resilience, the paper will use descriptive statistics examining how these figures changed for the eight NUTS 3 regions in Ireland over the period 2000-2014. In order to compare these regions, the figures are equalised at a base year and the changes are analysed over the time frame. This is done for two separate time frames. Firstly, 2000 is used as the base year and the time frame of 2000 to 2014 is analysed. This gives an idea of the growth trajectories that the eight regions were on before the great recession struck. Then, the year 2007 is used as the base year and the time frame of 2007 to 2014 is analysed. This provides a more in-depth view of what happened during and after the recession. All the calculations were done by the author using data from the Eurostat database.

Studies have found many different factors that affect resilience. Urban regions and regions that have better accessibility have been found to be more resilient (ESPON 2014; Lapuh 2018). Of the eight NUTS 3 regions in Ireland there is only one urban region, as defined by the European Commission, which is Dublin. The second largest city in Ireland is Cork, located in the SouthWest, and the third city is Galway, located in the West. So, if urban regions are more resilient in the Irish context, we should see these three regions (Dublin, South-West and West) respond better to the crisis. Other factors that are often found to be relevant, such as institutions or social capital, have not been analysed as the data doesn't exist at a NUTS 3 level. 


\section{The Irish economy before and after the great recession}

As stated above, the media has often represented Ireland's experience during and since the great recession as somehow spectacular. The purpose of this section is to briefly look at the Irish economic experience during the time period from 2000 to 2014 using three indicators of economic strength: GDP per capita (PPP), GVA, and employment. Employment will be measured by both the number of people employed, and the number of hours worked. To give some perspective to the Irish case these indicators will be compared to those of Portugal, Italy, Greece and Spain. These four countries, along with Ireland, have been referred to as the 'PIIGS' and considered the countries in the EU that have been most negatively affected by the great recession.

The first indicator to be analysed is GDP per capita (PPP). Fig. 1 uses 2000 as a base year and shows the relative changes in GDP per capita for the five countries over the fourteen years. As can be seen in the graph, Ireland, Spain and Greece appear to be on a higher growth trajectory with their economies growing by over $40 \%$ in the seven years leading up to the great recession. Portugal and Italy had more modest growth with their economies growing $28 \%$ and $18 \%$ respectively, in the run up to the recession. Fig. 2 uses 2007 as the base year to show the effects of the recession on the GDP per capita for the five countries. As can be seen in both graphs, Ireland experienced the

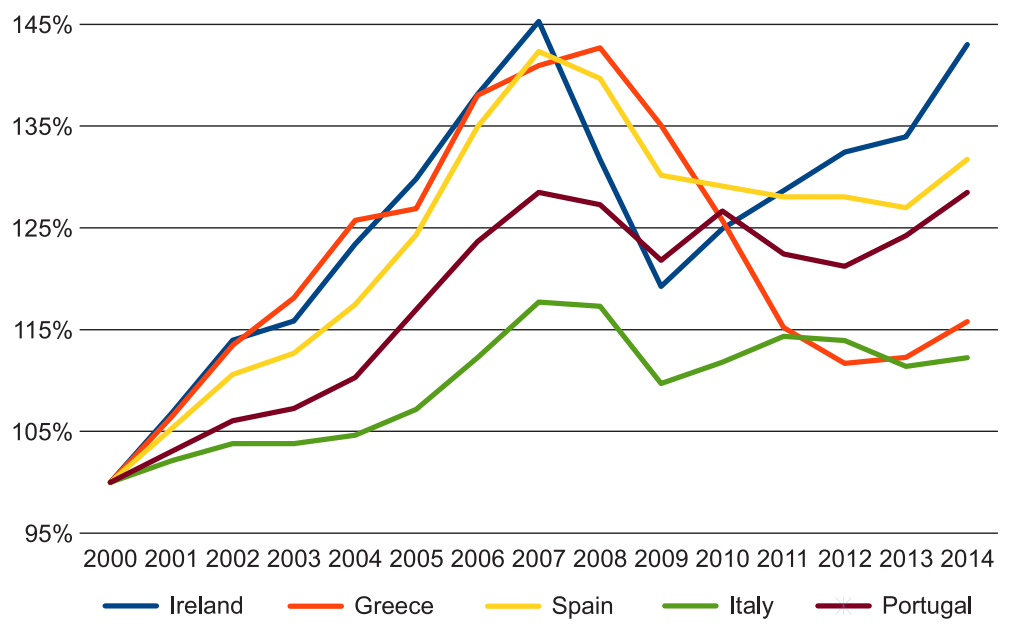

Fig. 1. Relative change in GDP per capita (PPP) for 'PIIGS' since 2000. Source: own study based on Eurostat data.

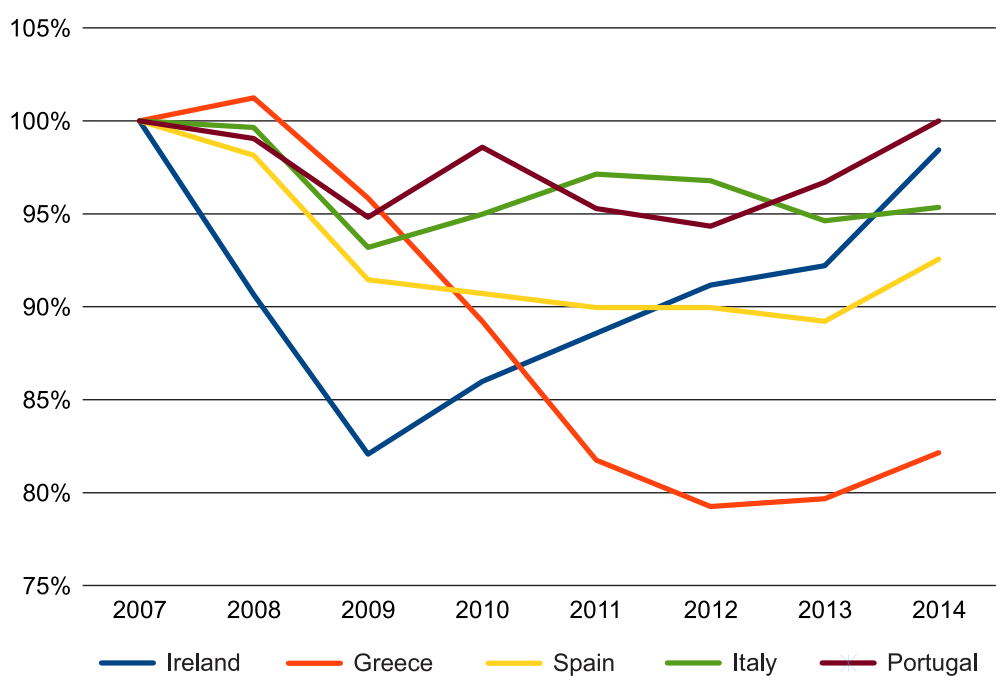

Fig. 2. Relative change in GDP per capita (PPP) for 'PIIGS' since 2007. Source: own study based on Eurostat data. 
sharpest initial decline from the great recession, in only two years its GDP per capita fell to $82 \%$ of its peak in 2007. Greece seems to have the most long-lasting affects, although their GDP per capita seemed to stabilise in the last few years of the time frame, there still has been no strong growth. Portugal and Italy seem to have been the least affected, with their GDP per capita only falling to $95 \%$ and $93 \%$ of their peak levels respectively.

To examine another measure of productivity of the economies we analyse the affect that the great recession had on gross value added (GVA). GVA is defined as output minus intermediate consumption and is considered a useful measurement of an economy's productivity. As can be seen in Fig. 3, Ireland grew exceptionally well in the run up to the recession, growing by almost $40 \%$ in the years 2000 to 2007. Spain and Greece also witnessed strong growth $25 \%$ and $27 \%$ respectively. Looking at Fig. 4 we can see that Ireland was initially affected negatively but has seen strong growth and is the only country to reach its peak pre-crisis level; by 2014 Ireland had almost reached $110 \%$ of its 2007 level. Portugal, Italy and Spain have all had moderately negative affects but seem to have stabilised within the 90\% to $95 \%$ level. Greece is the country that was worst affected in the 2007 to 2014 time-frame, falling below $75 \%$.

Another important indicator for measuring the strength of an economy is employment. Due to the increase in atypical work (defined as

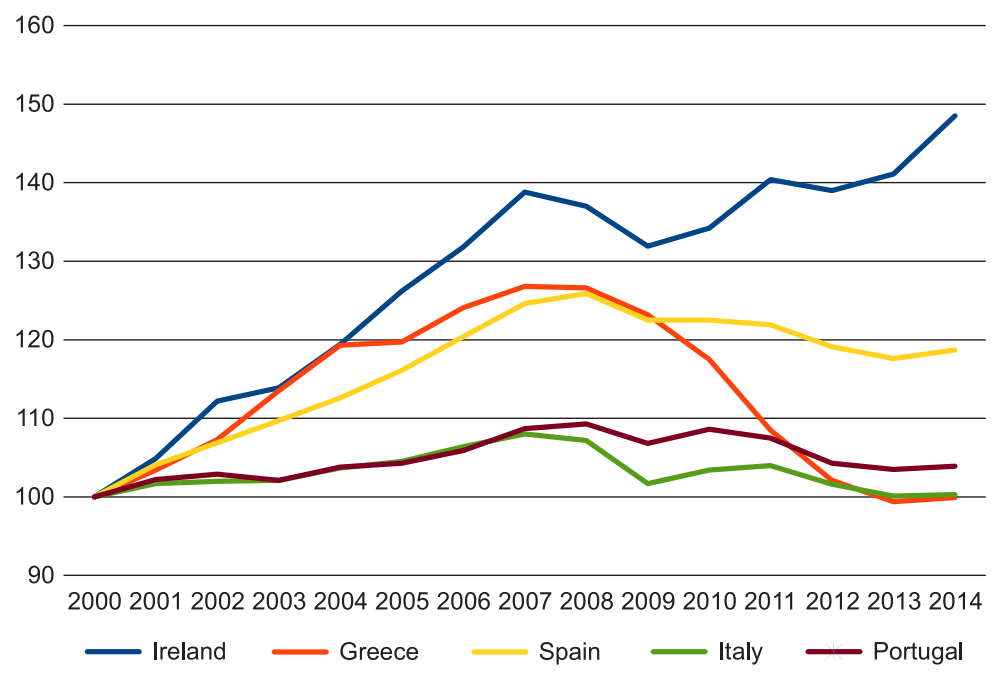

Fig. 3. Relative change in GVA for 'PIIGS' since 2000. Source: own study based on Eurostat data.

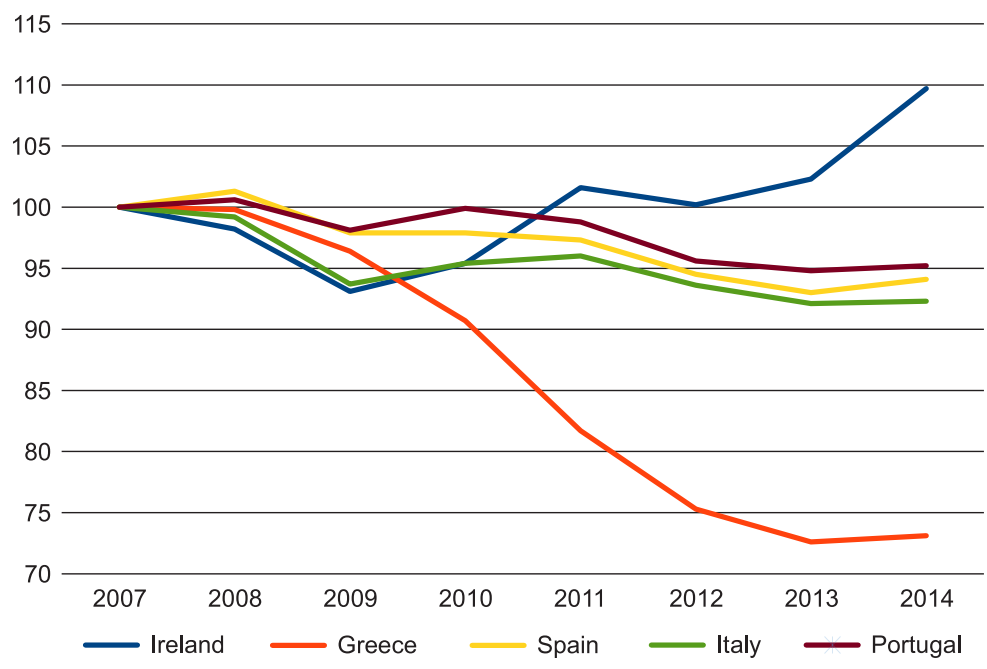

Fig. 4. Relative change in GVA for 'PIIGS' since 2007. Source: own study based on Eurostat data. 


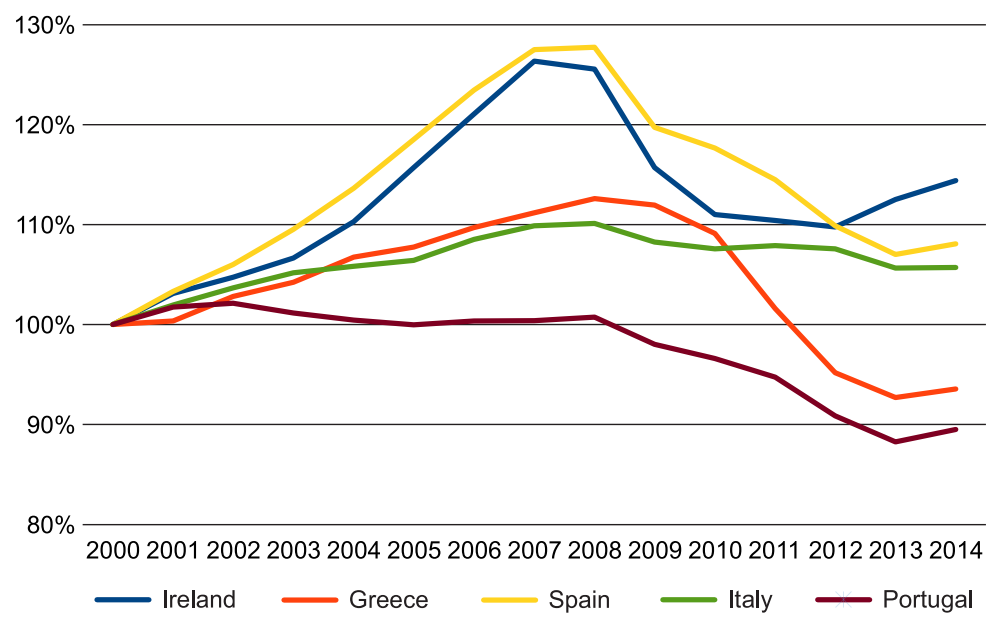

Fig. 5. Relative change in the number of employed persons in 'PIIGS' since 2000. Source: own study based on Eurostat data.

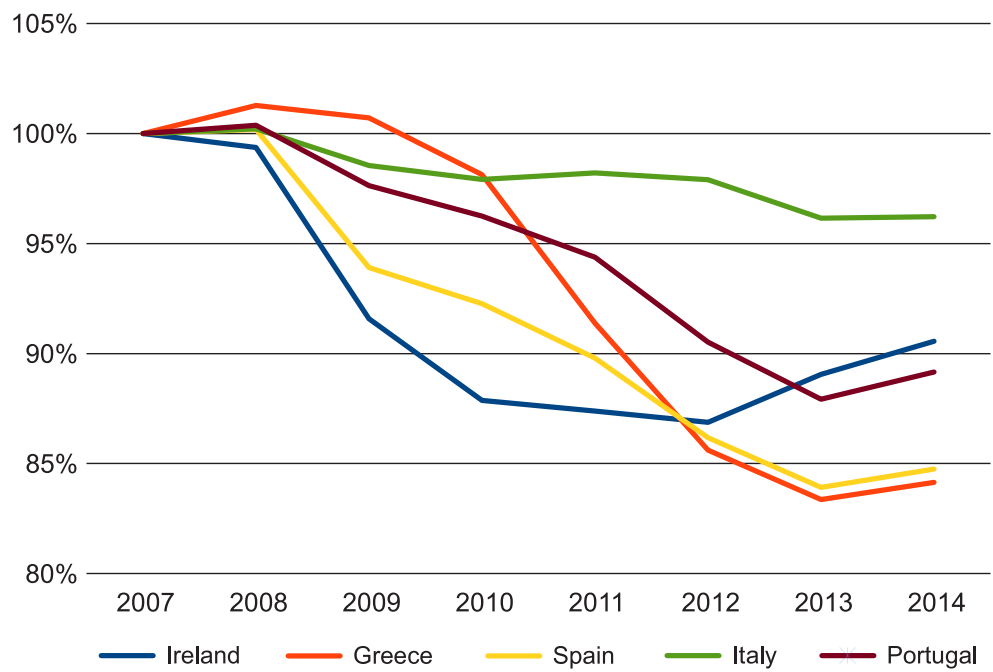

Fig. 6. Relative change in the number of employed persons in 'PIIGS' since 2007. Source: own study based on Eurostat data.

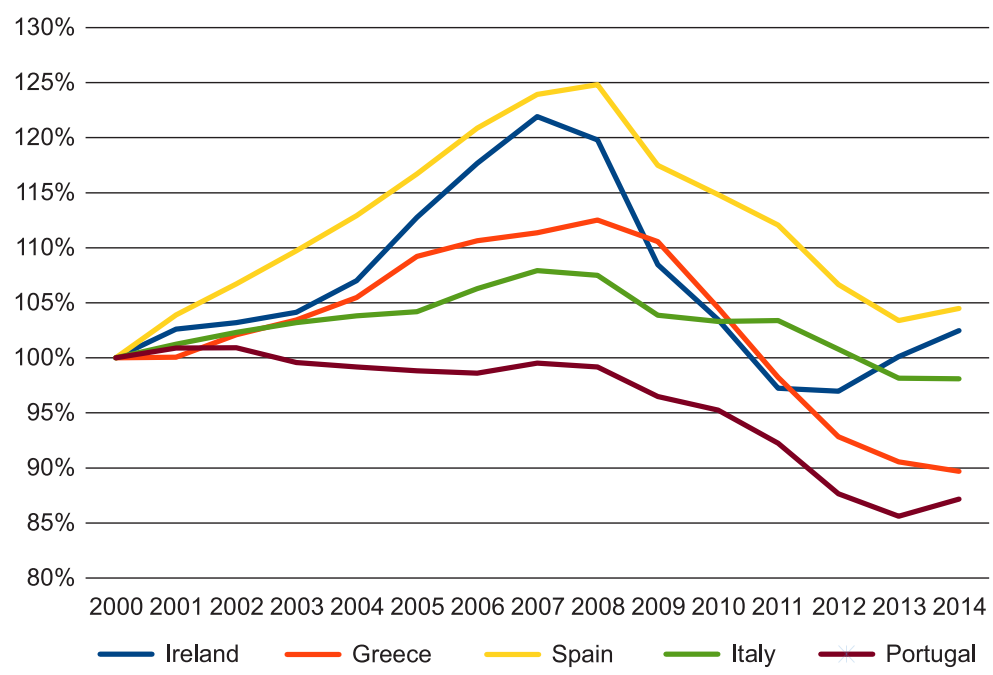

Fig. 7. Relative change in the number of hours worked in 'PIIGS' since 2000. Source: own study based on Eurostat data. 


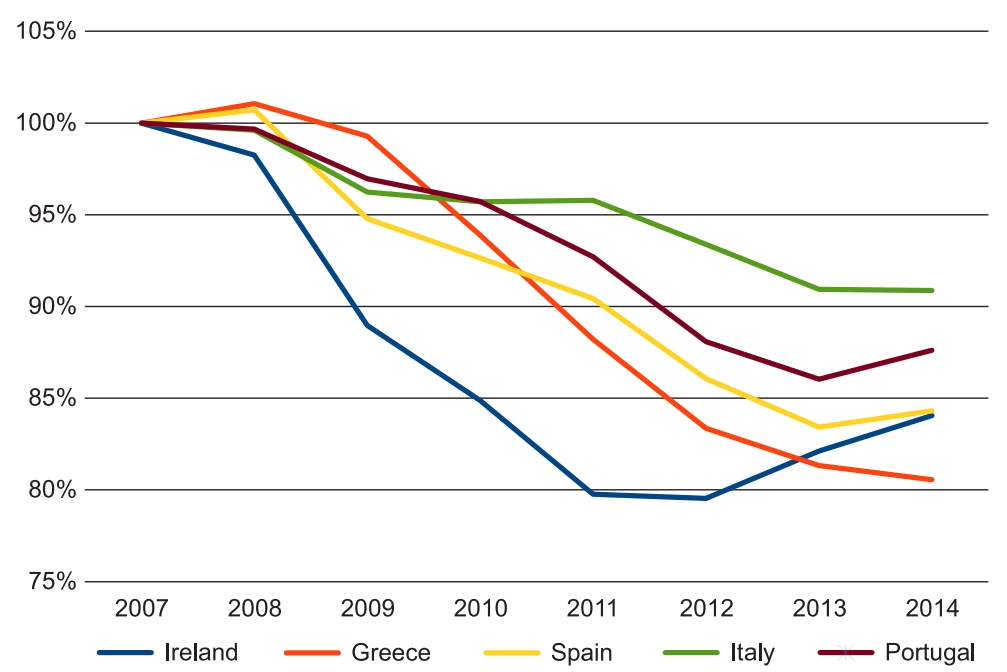

Fig. 8. Relative change in the number of hours worked in 'PIIGS' since 2007. Source: own study based on Eurostat data.

part-time and temporary work) during and after the recession (Kelly, Barrett 2017), it is important to look not only at the number of people employed, but also at the number of hours worked. Fig. 5 and Fig. 6 look at the relative changes in the number of people employed in the five countries using 2000 and 2007 as the base years respectively. As can be seen in the run up to the great recession, Ireland and Spain both had strong growth in the number of people employed, growing by close to $30 \%$. Italy and Greece both grew by about $10 \%$ while Portugal didn't witness any strong growth in the 2000 to 2007 time-frame and seemed to remain relatively stable. Ireland had the worst initial decline in employee numbers but seems to have returned to relatively strong growth since 2012. Italy appears to be the least affected by the recession in terms of the number of people employed.

Fig. 7 and Fig. 8 represent changes in the number of hours worked. We generally see a similar trend as to that of the number of people employed, however Ireland's recovery doesn't appear to be as strong. This is most likely due to the rise in atypical work which is confirmed by the work of Kelly and Barrett (2017).

\section{Regional disparities and regional resilience in Ireland}

This section will analyse the changes in disparities across Irish regions from 2000 to 2014 and the extent to which urban regions have shown greater resilience. This will show if there is any evidence to the claims that Ireland's recovery has been a two-tier recovery with the recovery being concentrated in Dublin (and other urban areas) while rural regions fall further behind. This section will examine changes in GDP per capita, GVA and employment across the eight NUTS 3 regions of Ireland. All calculations were done by the author using data from the Eurostat database.

Fig. 9 shows the GDP per capita for the eight regions as a percent of the national figure over the time frame 2000 to 2014 . There are only two regions above the national figure, Dublin and the South-West (this is where the second largest city, Cork city, is located). The other six regions are below the national figure. Since 2007, Dublin seems to be growing further from the national figure while the two poorest regions (the Border and Midland regions) are falling further behind. In an attempt to verify this, Fig. 10 shows the arithmetic mean deviation of regional GDP per capita from the national figure. This deviation has grown from $25 \%$ to $37 \%$. That is to say, that in 2000 regions were on average $25 \%$ different from the national level of GDP per capita and in 2014 they were $37 \%$ different. This is a sign that Ireland has witnessed an increase in regional disparities over the 14 years but what is striking about this graph is that the upward trend corresponds with the start of the recession.

Fig. 11 uses a method similar to Dyba et al. (2018) and Barro (1997) to test for convergence among Irish regions during the period. The $x$-axis represents the log of GDP per capita in 2000 
for the eight regions, while the y-axis represents the average annual growth rates from 2000 to 2014. The steep upward slope and the high value of the r-squared figure indicate a strong sign of divergence. This test is considered more appropriate for long-run growth and the fact that Ireland only has eight regions, which is a small number of observations, means that the results of

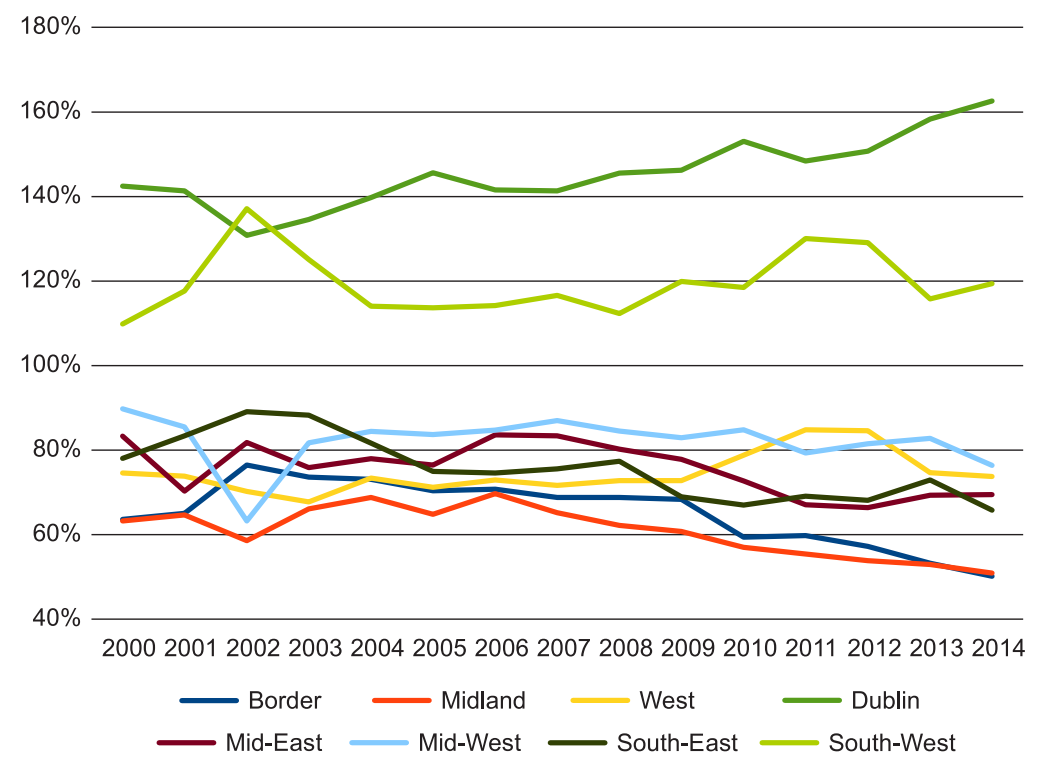

Fig. 9. Regional GDP per capita (PPP) as a percent of the national figure. Source: own study based on Eurostat data.

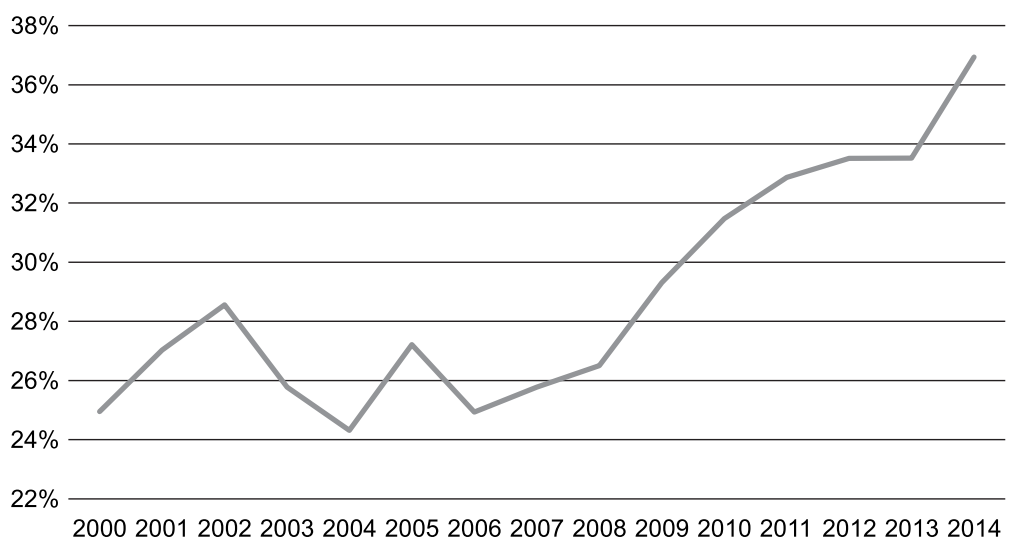

Fig. 10. Mean deviation of regional GDP per capita (PPP) from the national level. Source: own study based on Eurostat data.

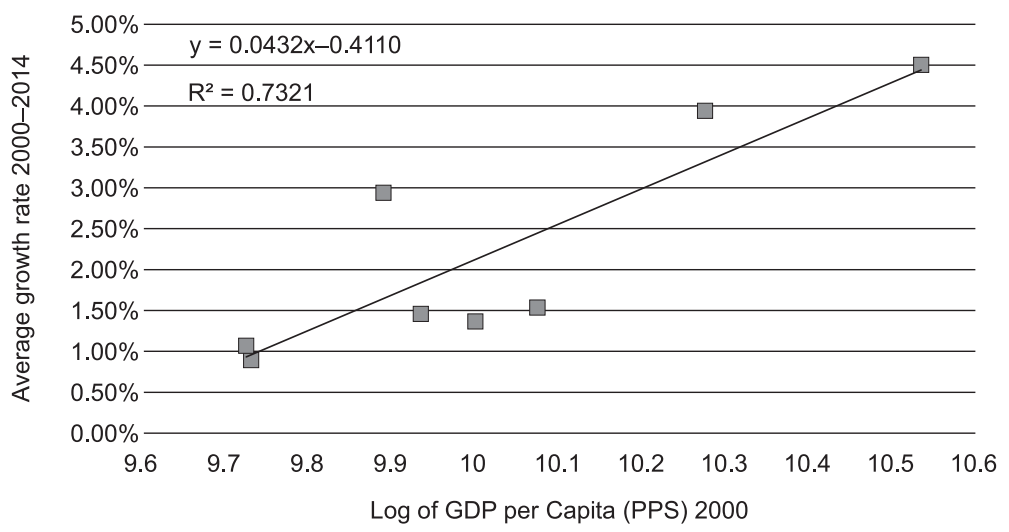

Fig. 11. Test for convergence among Irish NUTS3 regions 2000-2014.

Source: own study based on Eurostat data. 
this test are open to scrutiny. However, this is still a worrying sign for regional disparities in Ireland and another indication that the recovery has not been evenly distributed across the country.

Another important indicator to measure the regional resistance is GVA, as is used by Lapuh (2018), as this is considered an important measurement of productivity in an economy. Fig. 12 presents the relative changes in GVA using 2007 as a base year. This graph shows that only Dublin, the South-West and the West have returned to their pre-crisis peak levels. The two regions experiencing the largest negative effects are the Border and Midland regions, with the Border region still showing no signs of growth.

The number of hours worked is not available at a NUTS 3 level which means for employment we only have the number of people employed as an indicator. It is important to note that this does not allow for atypical work, which may affect some regions more than others. Fig. 13 and 14 show the relative changes in the number of people employed for the eight NUTS 3 regions using 2000 and 2007 as the base years respectively. The Mid-East region showed the strongest pre-crisis increase, growing by close to $40 \%$. This differs

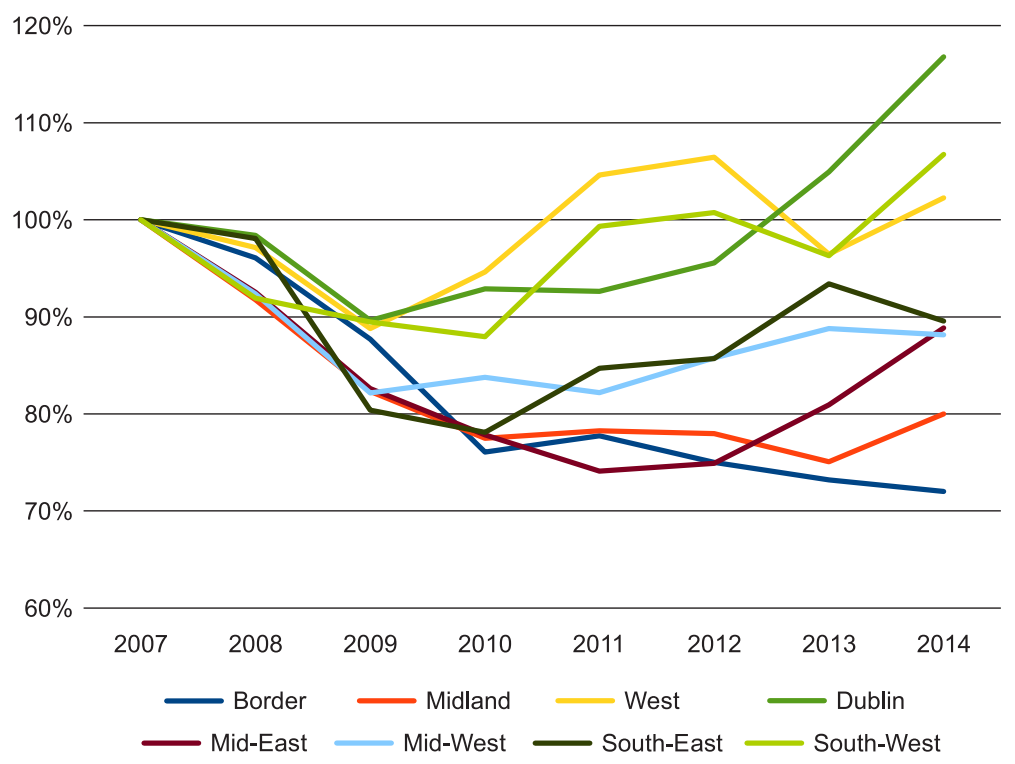

Fig. 12. Relative change in GVA for Irish regions since 2007. Source: own study based on Eurostat data.

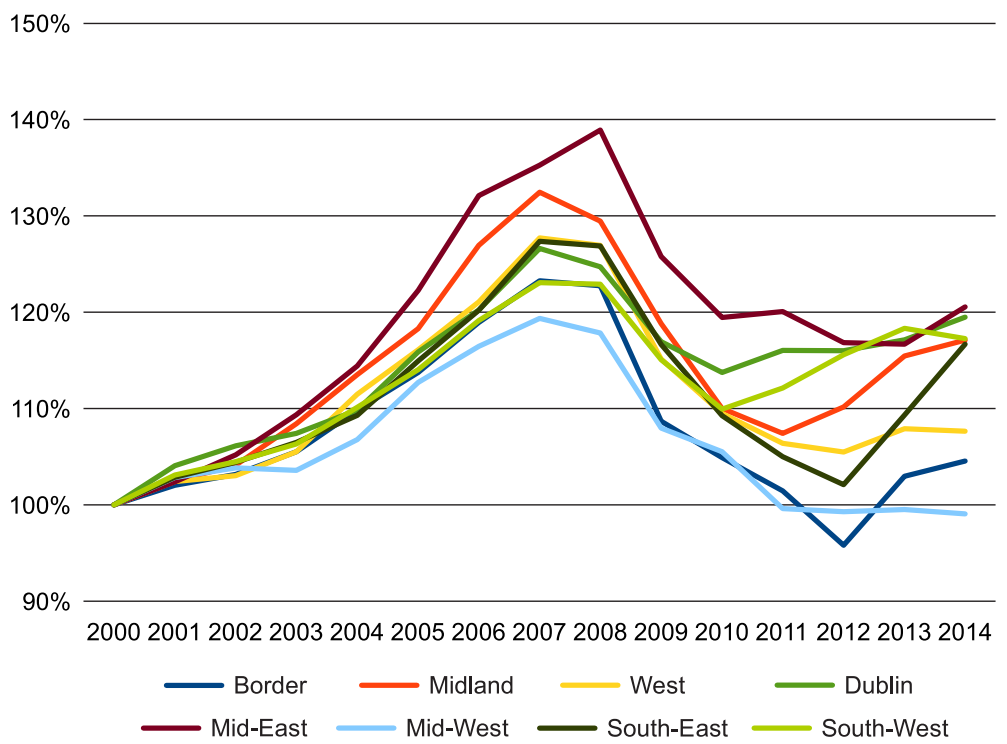

Fig. 13. Relative change in the number of people employed in Irish regions since 2000. Source: own study based on Eurostat data. 


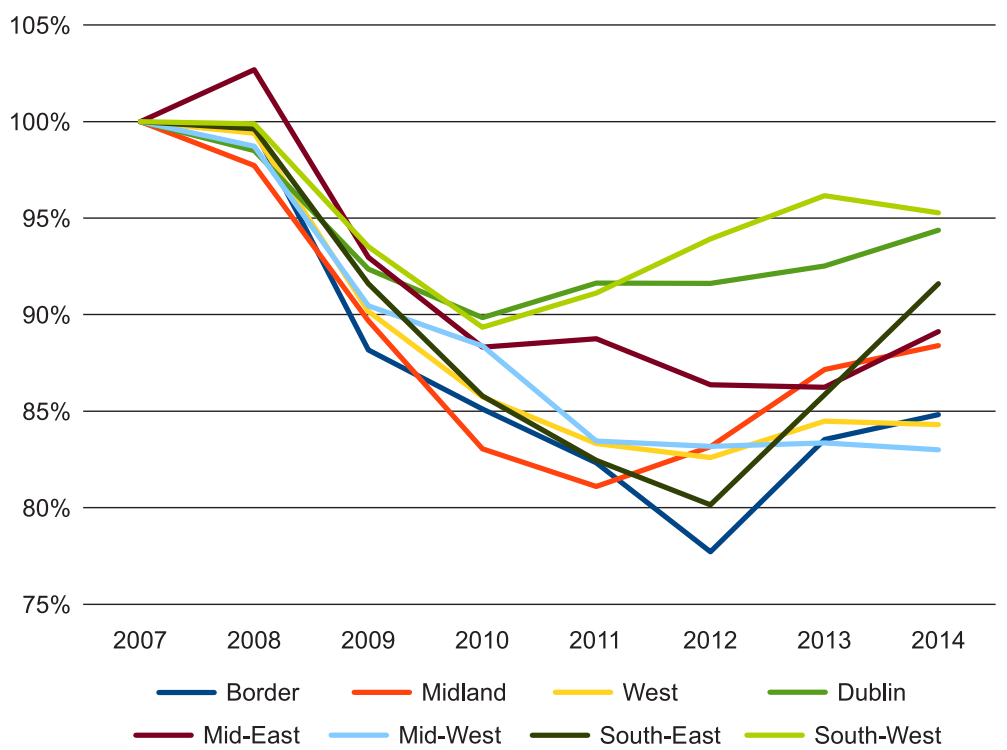

Fig. 14. Relative change in the number of people employed in Irish regions since 2007. Source: own study based on Eurostat data.

considerably from the change in GDP per capita in the Mid-East region. This indicates that the Mid-East region is most probably a commuter region. As it is located surrounding the Dublin region it is likely that a large number of people commute from the Mid-East region to Dublin. Dublin and the South-West have shown strong signs of recovery. The South-East saw one of the largest declines but showed strong growth in 2013 and again in 2014.

\section{Discussion and conclusion}

As can be seen when compared to the economies of the other 'PIIGS' countries, Ireland was initially affected more negatively by the great recession with a greater drop in GDP per capita and employment in the initial years. However, Ireland's recovery has been relatively quick compared to the other 'PIIGS'. This confirms other studies of the Irish recovery such as Fitzgerald (2014: 8) which found "clear signs that the economy began to grow again in 2012 and this recovery has continued through 2013 and 2014". Ruane (2016: 249) has attributed the strong recovery in Ireland to the "large, foreign-owned, modern, export-orientated, multinational sector". The question now is to what extent that recovery has been concentrated in Dublin and other urban centres or has the recovery been equitably distributed across Irish regions.
The arithmetic mean deviation of regional GDP per capita from the national figure has grown from $25 \%$ to $37 \%$ between 2000 and 2014 which would imply that the recession has had a negative impact on regional disparities in Ireland. This suggests that Dublin and the SouthWest have been more resilient, as they are the only regions with above average GDP per capita.

In terms of GVA, the only regions that have returned to pre-crisis levels are Dublin, the SouthWest and the West, these are the regions with the largest cities (Dublin, Cork and Galway respectively). In terms of employment the two regions that have rebounded strongest from the great recession have been Dublin and the South-West. Despite showing strong signs of recovery with respect to GDP per capita and GVA, the West has shown weak signs in terms of the number of people employed.

Breathnach (2015) looks at regional resilience in Ireland by analysing employment in firms in receipt of assistance from the state's enterprise agencies. The results of this section confirm Breathnach's findings that Dublin, Cork and Galway were the most resilient regions following the great recession. This would indicate that there is truth behind the idea that Ireland is experiencing a two-tier recovery with urban centres recovering faster and rural regions falling behind. Morgenroth (2014) states that regional divergence during the recovery in Ireland is part of a longer trend of divergence caused by 
agglomeration economics. There are also studies from other countries that find growth to be faster in urban areas, such as Churski (2014: 75) which finds that from 2000 to 2010 "growth areas in Poland correspond to metropolitan and highly industrialised areas". The evidence from this study suggests that, even if the urban-rural divide in Ireland is part of a longer trend, the great recession has accentuated the division resulting in larger regional disparities in Ireland. Therefore, we find that the idea of a two-tier recovery in Ireland is valid.

This paper has been a case study of Irish regional economic resilience since the great recession using descriptive statistics. The Irish case is an interesting one to study, being a small country with one large, highly concentrated city. The economy was initially hit hard by the great recession, but the quick recovery has been referred to as the 'Celtic Phoenix'. Compared to other countries similarly affected by the recession this name seems justified. However, focusing solely on the success of the economy as a whole, ignores the rising regional disparities within the country. There is validity to the claims of a two-tier recovery. Dublin has recovered strongly, and to a lesser extent so have the South-West and West but the majority of regions in the country have yet to feel the benefits of the strong growth rates.

Further research into regional disparities in Ireland should focus on the factors that lead to regional resilience. International research from cross country studies (ESPON 2014) and from individual countries (Dokic et. al. 2016; Lapuh 2018) have found several factors that lead to regional resilience and these factors should be explored from an Irish case. ESPON (2014) find that the foundations of regional economic resilience can be divided into four broad categories: business, people, place and community. It is recommended that these four categories be researched within the Irish context to help further explain the increase in regional disparities in Ireland since the great recession.

\section{Acknowledgements}

This research has received funding from the European Union's Horizon 2020 research and innovation programme under the Marie SkłodowskaCurie grant agreement number 721999 .
I would also like to thank the two anonymous reviewers as well as prof. Tadeusz Stryjakiewicz, prof. Artur Bajerski and prof. Maria de Fatima Ferreiro for their helpful comments on an earlier version of this paper.

\section{References}

Barro R., 1997. Determinants of economic growth. A cross-country empirical study. MIT Press, Cambridge, Massachusetts, USA.

Berkes F., Folke C., 1998. Linking social and ecological systems: Management practices and social mechanisms for building resilience. Cambridge University Press, Cambridge.

Brady A., 2014. Rise of the Celtic Phoenix. Shelflife. https:/ / www.shelflife.ie/rise-of-the-celtic-phoenix/ (accessed: 16 September 2014).

Breathnach P., van Egeraat C., Curran D., 2015. Regional economic resilience in Ireland: The roles of industrial structure and foreign inward investment. Regional Studies, $R e$ gional Science 2(1): 497-517. http:/ / dx.doi.org/10.1080/2 1681376.2015.1088792

Churski P., 2014. Variations in the spatial distribution of areas of economic growth and stagnation in Poland: Determinants and consequences. Quaestiones Geographicae 33(2): 63-77.

Davoudi S., 2012. Resilience: A bridging concept or a dead end? Planning Theory and Practice 13(1): 299-307.

Dokic I., Frohlich Z., Bakaric I.R., 2016. The impact of the economic crisis on regional disparities in Croatia. Cambridge Journal of Regions, Economy and Society 9(1): 179-195. https://doi.org/10.1093/cjres/rsv030

Dyba W., Loewen B., Looga J., Zdražil P., 2018. Regional development in Central-Eastern European countries at the beginning of the 21st century: Path dependence and effects of EU Cohesion Policy. Quaestiones Geographicae 37(2): 77-92.

Easterlin R., 1958. Long term regional income changes: Some suggested factors. Papers and Proceedings of the Regional Science Association, Volume IV: 313-325

Eurostat, 2018. Database. Online: ec.europa.eu/eurostat/ data/database (accessed: 25 February 2018).

ESPON, 2014. ECR2 - Economic crisis: Resilience of regions. Scientific Report. Luxembourg: ESPON.

Fitzgerald J., 2014. Ireland's recovery from crisis. CESifo Forum 2 (June).

Hassink R., 2010. Regional resilience: A promising concept to explain differences in regional economic adaptability? Cambridge Journal of Regions, Economy and Society 3: 45-58.

Holling C.S., 1973. Resilience and stability of ecological systems. Annual Review of Ecological Systems 4: 1-23.

Holling C.S., 1996. Engineering resilience versus ecological resilience, In: Schulze P.C. (ed.), Engineering within ecological constraints. National Academy Press, Washington, DC: 31-44.

Kelly E., Barrett A., 2017. Atypical work and Ireland's labour market collapse and recovery. The Economic and Social Review 48(4): 463-488.

Krugman P., 1991. Increasing returns and economic geography. Journal of Political Economy 99(3): 483-499.

Lupah L., 2018. Socio-economic characteristics of resilient localities - experiences from Slovenia. Regional Studies, 
Regional Science 5(1): 149-156. https:/ / doi.org/10.1080/2 1681376.2018.1459202

Martin R., 2012. Regional economic resilience, hysteresis and recessionary shocks. Journal of Economic Geography 12(1): 1-32. https://doi.org/10.1093/jeg/lbr019

Martin R., Sunley P., 2015. On the notion of regional economic resilience: Conceptualization and explanation. Journal of Economic Geography 15(1): 1-42. https://doi. org/10.1093/jeg/lbu015

Morgenroth E., 2014. Two-speed recovery? Spatial development in Ireland. ESRI Research Notes 4/2.

O'Hora A., Kelpie C., 2014. German finance minister Wolfgang Schaeuble: Germany jealous of Irish growth figures. The Independent. https://www.independent.ie/business/irish/german-finance-minister-wolfgang-schaeuble-germany-jealous-of-irish-growth-figures-30707713. html (accessed: 31 October 2014).
Reilly J., 2014. Ireland is spending nation once again as Celtic Phoenix rises. The Independent. https://www.independent.ie/irish-news/news/ireland-is-a-spending-nationonce-again-as-celtic-phoenix-rises-30531688.html (accessed: 24 August 2014).

Ruane F., 2016. Ireland - a remarkable economic recovery? The Australian Economic Revieww 49(3): 241-250.

Simmie J., Martin R., 2010. The economic resilience of regions: Towards an evolutionary approach. Cambridge Journal of Regions, Economy and Society 3(1): 27-43. https://doi. org/10.1093/cjres/rsp029

Solow R., 1956. A contribution to the theory of economic growth. The Quarterly Journal of Economics 70(1): 65-94.

Weston C., 2015. Urban-rural divide widens as capital booms. The Independent. https://www.independent.ie/ business/personal-finance/property-mortgages/urbanrural-divide-widens-as-capital-booms-31167364.html (accessed: 24 April 2015). 